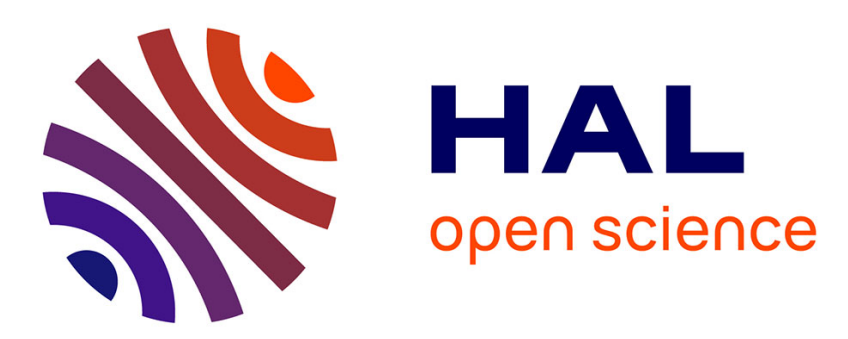

\title{
Evaluation of Cladding Residual Stresses in Clad Blocks by Measurements and Numerical Simulations
}

\author{
P. Dupas, D. Moinereau
}

\section{To cite this version:}

P. Dupas, D. Moinereau. Evaluation of Cladding Residual Stresses in Clad Blocks by Measurements and Numerical Simulations. Journal de Physique IV Proceedings, 1996, 06 (C1), pp.C1-187-C1-196. 10.1051/jp4:1996118 . jpa-00254150

\section{HAL Id: jpa-00254150 https://hal.science/jpa-00254150}

Submitted on 1 Jan 1996

HAL is a multi-disciplinary open access archive for the deposit and dissemination of scientific research documents, whether they are published or not. The documents may come from teaching and research institutions in France or abroad, or from public or private research centers.
L'archive ouverte pluridisciplinaire HAL, est destinée au dépôt et à la diffusion de documents scientifiques de niveau recherche, publiés ou non, émanant des établissements d'enseignement et de recherche français ou étrangers, des laboratoires publics ou privés. 


\title{
Evaluation of Cladding Residual Stresses in Clad Blocks by Measurements and Numerical Simulations
}

\author{
P. Dupas and D. Moinereau \\ Research and Development Branch, EDF, Centre des Renardières, Route de Sens, BP. I, \\ 77250 Moret-sur-Loing, France
}

\begin{abstract}
Reactor pressure vessels are internally clad with austenitic stainless steel. This welding operation generates residual stresses which can have an important role in integrity assessments. In order to evaluate these stresses, an experimental and numerical programme has been conducted. The experiments includes cladding operations, macrographic analyses, temperature and residual stresses measurements with different methods. According to these measurements, transversal stresses (perpendicular to the welding direction) and longitudinal stresses (parallel to the welding direction) are highly tensile in stainless steel and they are compressive in the HAZ. Finite element calculations were used to simulate both welding operations and post weld heat treatment. These calculations coupled the thermal, metallurgical and mechanical aspects in a $2 \mathrm{D}$ representation. Different models were studied including effect of generalised plane strain, transformation plasticity, creep and tempering. The transversal stresses calculated are similar to the measured ones, but the longitudinal stresses showed to be very sensitive to the model used. As expected because of the two-dimension model, the longitudinal stresses can't be well estimated. More work is needed to improve measurements of stresses in depth (important differences appeared between the different methods). A predictive model would be also very useful to determine the thermal loading which is at present dependant on measurements. $\dot{A}$ 3D calculation appears to be necessary to evaluate longitudinal stresses.
\end{abstract}

\section{INTRODUCTION}

A research programme was started in 1987 at EDF, concerning flaw assessment in nuclear reactor pressure vessels, and more particularly the assessment of cracks in and under the cladding. This required to evaluate residual stresses induced by the cladding welding operation and the following post weld heat treatment (PWHT).

With this purpose, several mock-ups in ferritic steel (SA508) were clad with one or two layers of austenitic stainless steel (A308L-A309L). Some of these mock-ups were then submitted to a PWHT. During cladding, temperature measurements were performed. After welding, macrographic analyses helped to study the heat affected zone (HAZ). Welding residual stresses were measured on a one layer mock-up using different methods : block removal, splitting and layering method (Leggatt [1]) and ringcore method (Kockelmann [2]). Residual stresses were also measured after the PWHT (Kockelmann [3]).

Using the finite element programme SYSWELD [4], we simulated the cladding of three beads in two layers and the post weld heat treatment. These calculations coupled the thermal, metallurgical and mechanical aspects of welding, e.g. Dubois [5], in a 2D representation. Different models (plane strain, generalised plane strain, transformation plasticity) have been used in mechanical calculations. To simulate the PWHT, we used either simple (thermoplastic cycle) and more complex models (tempering, creep).

\section{EXPERIMENTAL PROCEDURE AND RESULTS}

Blocks were clad using a submerged arc strip welding process (Fig. 1). The block was heated up to $170^{\circ} \mathrm{C}$ before welding and remained at this temperature between each bead. Beads are $60 \mathrm{~mm}$ wide, 3.5 to 4 thick and the overlap was approximately $7 \mathrm{~mm}$. A309L stainless steel was used for the first layer, A308L for the second layer while the block is representative of $\mathrm{SA} 508 \mathrm{Cl} 3$ nuclear reactor pressure vessel steel. 
Several blocks were clad, each one different from the others by dimensions, number of beads and layers. One block was instrumented with 12 thermocouples and the temperatures measured were used in the numerical simulations presented hereafter. Some of these measurements are shown in Fig. 2 and table 1 in comparison with numerical results.

\begin{tabular}{|l|l|l|l|}
\hline & $\mathrm{T}_{\max }\left({ }^{\circ} \mathrm{C}\right)$ & $\Delta \mathrm{t}_{800-500^{\circ} \mathrm{C}}(\mathrm{s})$ & Depth $(\mathrm{mm})$ \\
\hline Calculated & 1500 & 61 & 0 \\
Measured & $1300^{*}$ & 76,9 & 0 \\
\hline Calculated & 1222 & 61,7 & 1,3 \\
Measured & 1170 & 80,2 & 1,33 \\
\hline Calculated & 1109 & 61,5 & 2,5 \\
Measured & 1008 & 80,5 & 2,38 \\
\hline
\end{tabular}

Table 1. Comparison between measured and calculated maximum temperatures and cooling rates from 800 to $500^{\circ} \mathrm{C}$. Results are given for different depths under fusion line.

Using macrographics analyses of HAZ, it was possible to determine the size of HAZ and its global metallurgical structure. As the welding procedure is automatic, results were shown to be very reproducible.

Many residual stress measurements were made on these blocks but only some of them are presented. The aim of these measurements is to give the stress field in depth, from the surface to the end of the HAZ. Figures 3 and 4 present the transverse stresses (perpendicular to the welding direction) and the longitudinal stresses (parallel to the welding direction) measured on a block ( $510 \mathrm{~mm}$ long, $560 \mathrm{~mm}$ wide and $85 \mathrm{~mm}$ thick) with one layer and 9 beads. These measurements were performed by TWI using the block removal, splitting and layering method, e.g. Leggatt [1] and by MPA Stuttgart using the ring-core method, e.g. Kockelmann [2]. It can be seen that the results are somewhat different depending on the method used and the location of the measurement ( 3 different locations for MPA and 2 for TWI). Both longitudinal and transverse stresses have the same profile : high tensile in the weld metal, compressive in the HAZ and high tensile again at the end of the HAZ. These profiles appeared also to be always the same, whatever are the dimensions of the block, the welding parameters (width of electrode, energy of welding), the number of beads, etc. But values can be very different, depending on the measurement method used. Such differences are unfortunately very common when measuring residual stresses with different methods and are related to the hypothesis made by the methods which are not verified, to the precision inherent to the measurements and to a possible not exact reproducibility of the process and the residual stresses created.

Another mock-up with two-layer cladding was heat treated after welding in order to relieve residual stresses. Residual stresses were measured after heat treatment (Fig. 5), e.g. Kockelmann [3]. Stresses have the same profile as the ones measured in as-welded mock-ups. Values are similar, except maybe in the HAZ where stresses are higher (in absolute value) in the as-welded state. But we cannot consider that residual stresses are relieved after this heat treatment.

\section{NUMERICAL ANALYSIS}

The numerical analysis is performed using the finite element code SYSWELD [4]. The analyse is a complete thermal, metallurgical and mechanical one. The first calculation is thermometallurgically coupled. It gives temperatures and phase proportions in the structure at each instant. These results are then used as input data for the mechanical calculation. The thermal, metallurgical and mechanical steps described hereafter are repeated for the cladding of each bead. When the cladding is ended, the block is heat treated. The PWHT requires again a complete thermal, metallurgical and mechanical analysis.

The geometry used for simulations is usually a block with 3 beads and 2 layers (Fig. 6). The calculation in a $2 \mathrm{D}$ one, in a cross-section perpendicular to the welding direction. It assumes that a bead is deposited instantaneously.

\subsection{Thermal calculation}

As we do not have a model which could give temperatures fields from welding parameters, we need temperature measurements to fit with the numerical thermal loading. We decompose this loading in 3 steps :

- the weld metal and the fusion zone are heated from $170^{\circ} \mathrm{C}$ to $1500^{\circ} \mathrm{C}$ (fusion temperature) in 4 seconds. 


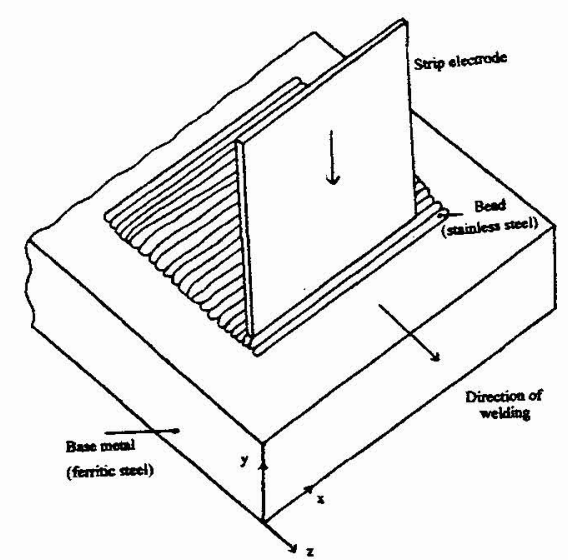

Figure 1: Schematic representation of submerged-arc cladding

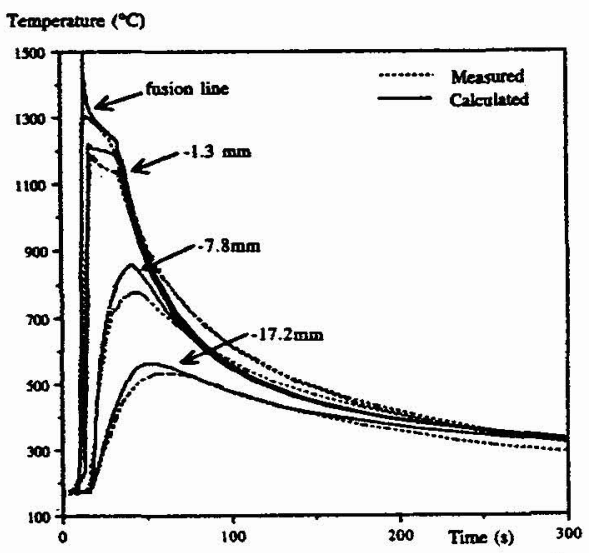

Figure 2: Measured and calculated temperatures at different depths

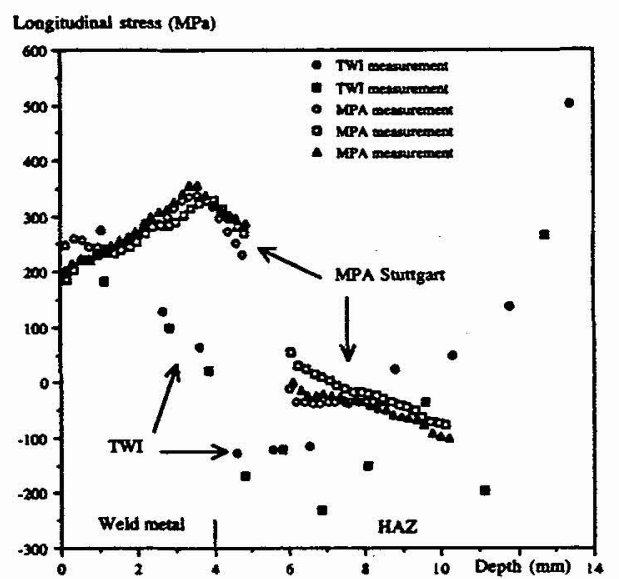

Figure 3: Longitudinal residual stress measurements after welding 


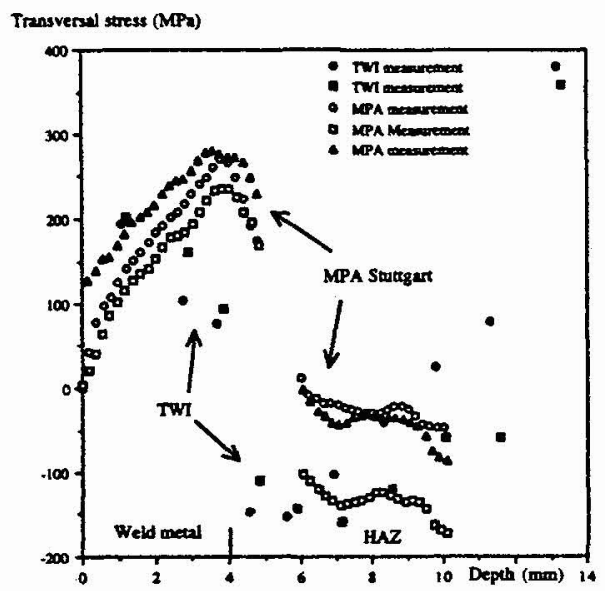

Figure 4: Transverse residual stress measurements after welding

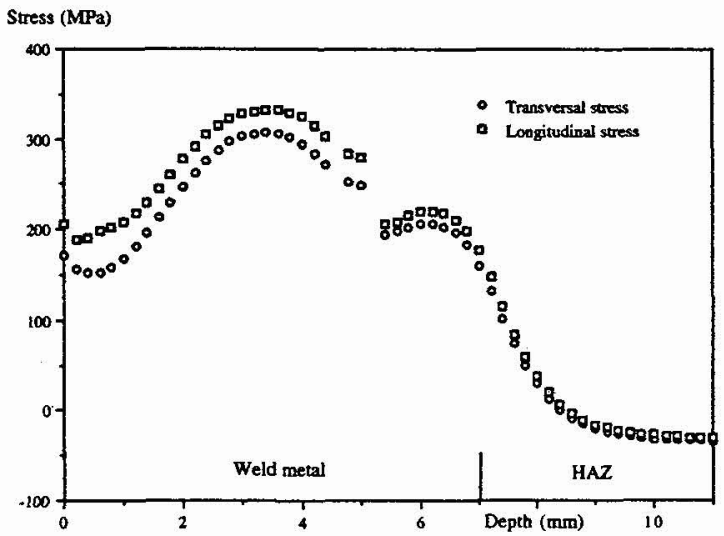

Figure 5: Residual stress measurements after PWHT

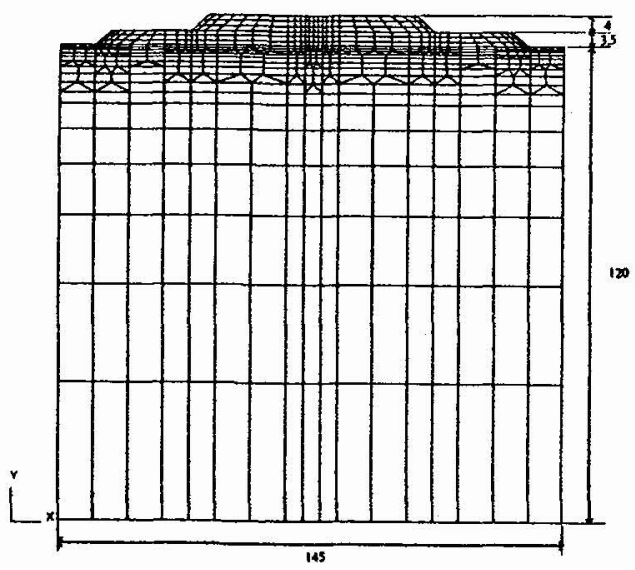

Figure 6: Dimensions and mesh of the calculated block 
- when the weld metal is liquid, we assume that the specific heat is ten times higher than that of the solid. We keep this metal in this state for 29 seconds.

- we let the entire structure cooling down to $170^{\circ} \mathrm{C}$, which is achieved in 2000 seconds.

This procedure is the same for each bead, but the time and maximum temperature values may change, depending on the layer (the second layer is welded with highest energy than the first one for metallurgical reasons).

We consider that thermal exchanges are mainly conductive because of the welding process (submerged arc) and the size of specimens, so convection phenomena is not taken into account, nor radiation.

\subsection{Metallurgical calculation}

Six different metallurgical phases are taken into account : austenite, ferrite (plus pearlite), bainite, tempered bainite, martensite and tempered martensite. The stainless steel stays austenitic throughout. The base metal starts from a mixed bainite and tempered bainite structure. During the heating, base metal at a temperature over $A_{c} 1$ begins to transform into austenite. During the cooling, it transforms into different phases (ferrite, martensite, bainite) depending on the rate of cooling. When as-welded phases (bainite and martensite) are heated again at temperatures under $A_{c 1}$, they may transform into tempered phases. These tempered phases are characterised by lower mechanical properties than as-welded ones.

The size of the fusion zone is determined a priori to be $0.6 \mathrm{~mm}$ deep. Measurements showed it was variable between 0 and $1.1 \mathrm{~mm}$.

\subsection{Mechanical calculation}

The behaviour of the base metal is assumed to be perfectly plastic, while the weld metal behaves in a Ramberg-Osgood type hardening way. Mechanical characteristics depend on temperature and metallurgical phases.

The results obtained with a plane strain model will be compared to the results with a generalised plane strain model. The consequence of taking or not taking account of the transformation plasticity will also be examined.

\subsection{Post weld heat treatment}

The block is heated from $170^{\circ} \mathrm{C}$ to $610^{\circ} \mathrm{C}$ at a rate of $30^{\circ} \mathrm{C} / \mathrm{hr}$. It is maintained at this temperature for 8 hours. It is then cooled down at a rate of $25^{\circ} \mathrm{C} / \mathrm{hr}$.

We consider that stresses are relieved in the following three ways :

- by plasticity because the yield stresses decrease with increasing temperature.

- by tempering hardened phases, the effect of which is the lowering of the mechanical properties and particularly the yield stress.

- by viscoplasticity when creep occurs.

\section{NUMERICAL RESULTS}

\subsection{Thermal results}

The evolution of temperature with time is presented in Fig. 2 for some nodes. These profiles are similar to the experimental ones. Two parameters are used to check the quality of the calculated temperatures (see table 1) : the maximum value (to have the $\mathrm{HAZ}$ well located) and the cooling speed between $800^{\circ} \mathrm{C}$ and $500^{\circ} \mathrm{C}$ (to have the right structural transformation). The comparison between numerical and experimental results shows some differences but the calculated values are considered to be precise enough for the calculation we perform.

\subsection{Metallurgical results}

The HAZ is mainly composed of as-welded bainite (fig. 7). This is confirmed by metallurgical examination of HAZ. The comparison of calculated and measured HAZ depth shows good agreement : $11.5 \mathrm{~mm}$ measured and $11.4 \mathrm{~mm}$ calculated for the first layer, $11.4 \mathrm{~mm}$ measured and calculated for the second layer. These values have not been used for fitting the thermal loading. So this result confirms that the numerical thermal loading is coherent with experiment ; particularly the $\mathrm{A}_{\mathrm{c} 1} 1$ line is well located. 


\subsection{Mechanical results}

The residual stresses are locally identical under a bead when this bead is deposited, as shown in Fig. 8 for the transverse stresses. But of course, the welding of a bead affects the stresses left by the previous beads, usually by relieving them as can be seen in Fig. 9, again for transverse stresses.

Figures 10 and 11 compare the profile of residual stresses with depth in the middle of the first bead after the deposit of the second bead, for three different mechanical models : plane strain without transformation plasticity, plane strain with transformation plasticity, generalised plane strain with transformation plasticity. It can be seen that results are qualitatively comparable for transverse residual stresses whatever the option used. But for longitudinal stresses, results in the HAZ depend strongly on the option used.

The effect of transformation plasticity is undoubtedly important by decreasing transverse stresses in the HAZ, as can be seen in Fig. 10 .

The generalised plane strain option seems to give better results (by comparison with measurements) than the plane strain one, for longitudinal stresses, according to the results shown in Fig. 11. With this model, the transverse and longitudinal stresses have the same profile, which is confirmed by measurements and literature, e.g. Schimoeller [6]. But these results are dependant on the size of the block simulated (Fig. 12) : when the block is wider, there are less differences between plane strain and generalised plane strain. These results show that the longitudinal stresses cannot be better evaluated with the generalised plane strain model than with the plane strain one. As all the measurements show that both transverse and longitudinal stresses are compressive in the HAZ, whatever the size of the block, we have to conclude that none of our 2D models is able to give the correct longitudinal stress independently of the size of the block. A 3D calculation is then necessary (but may be not sufficient).

\subsection{Post weld heat treatment results}

Figure 13 compare calculated transverse residual stresses before and after heat treatment, using different options. It can be seen that the maximum of relief is obtained when using the creep of the base metal. In fact, we even showed that when the creep model is used, it made no difference to use or not the tempering model : creep is the major cause of relieving. It may be underlined that we never obtained a free-stress state at $610^{\circ} \mathrm{C}$ (Fig. 14), even with the creep model and more than 10 hours of post weld heat treatment. The results presented here have been obtained in generalised plane strain, but they are identical with the plane strain option (for transverse stresses). We also showed that creep of weld metal was unimportant, compared to creep of base metal.

\section{SIMPLIFIED METHOD}

We call simplified method the method which consists of making the assumption that the structure has no residual stresses at $610^{\circ} \mathrm{C}$ (the temperature of the PWHT) and that the residual stresses are only due to the difference in expansion coefficient appearing between the base metal and the weld metal during cooling. This approach has been applied successfully in bimetallic junction by $\mathrm{H}$. Gamha and coll. [7], and validated in surface by comparison with measurements. The advantage of this method is to avoid a costly and difficult calculation of the welding operation when a PWHT is performed.

The results obtained with this method are presented on figure 15 , and compared with the results of the simulation of welding and PWHT. It can be seen that the results are similar except in the HAZ, where the effect of phase transformation cannot be reproduced by the simplified method. It has to be underlined that the materials and their mechanical properties are identical in the two approaches (we have introduce a HAZ in the simplified method) and the difference can then be explained only by the effect of phase transformations (through transformation plasticity).

\section{CONCLUSION}

The measurements of residual stresses after welding and after post weld heat treatment show that both transverse and longitudinal residual stresses have the same profile : high tension in the weld metal and at the end of the HAZ, compression in the HAZ. But values are dependent on the method used.

The numerical simulation of cladding with a complete thermal, metallurgical and mechanical approach appears to be useful to understand the way residual stresses are created. These calculations and measurements tend to prove that transverse residual stresses are compressive in the HAZ, as their sign in this area is independent of measurement method and model used for calculation. It has been shown that longitudinal stresses could not be well evaluated by the 2D model we used. 

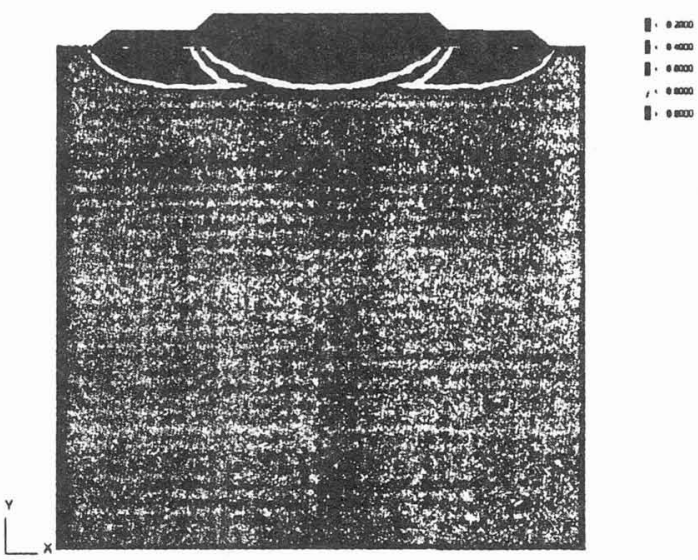

Figure 7: Isovalues of as-welded bainite after 3 beads.

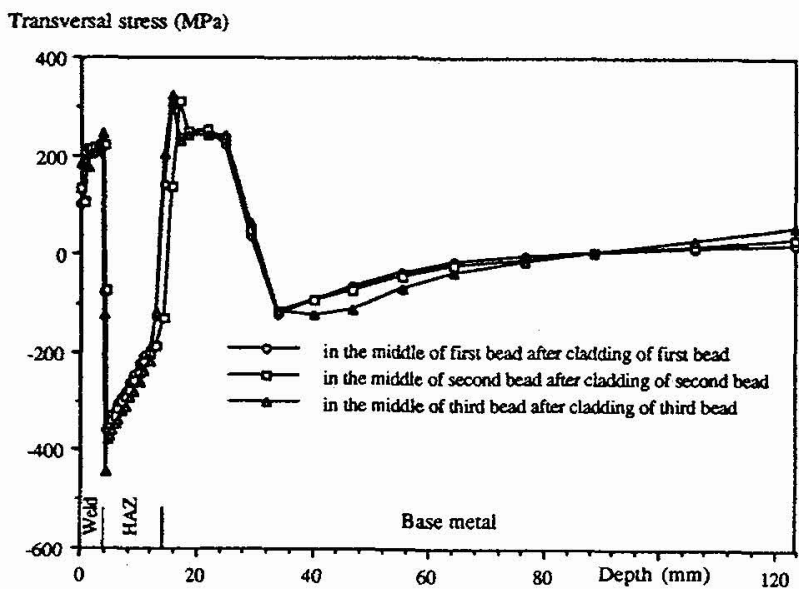

Figure 8: Transverse stress centred on each bead after cladding of each bead

Transversal stress (MPa)

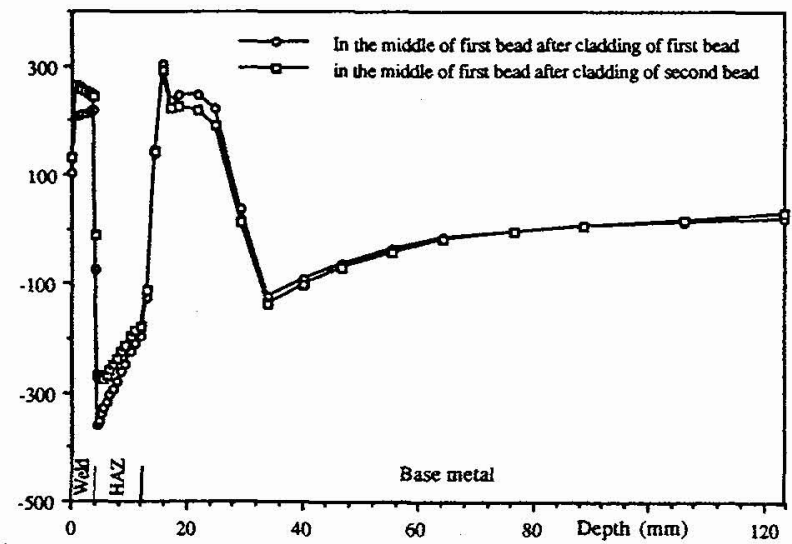

Figure 9: Transverse stress centred on first bead after cladding of first and second beads 


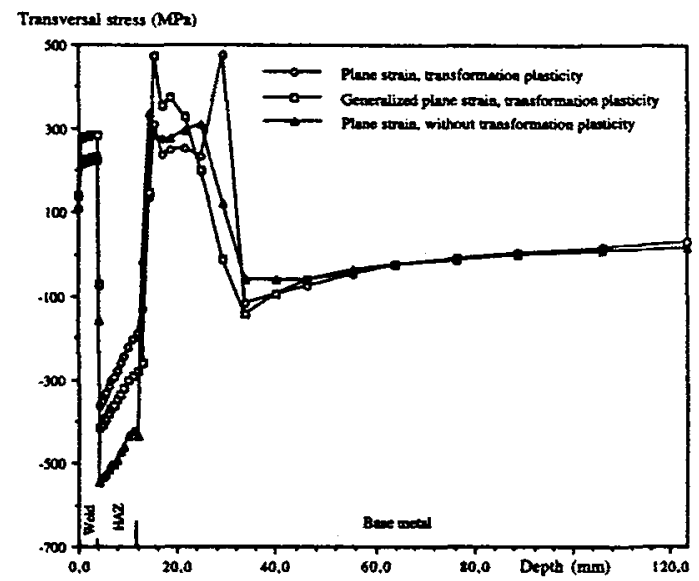

Figure 10: Transverse stress in depth centred on second bead with different mechanical models

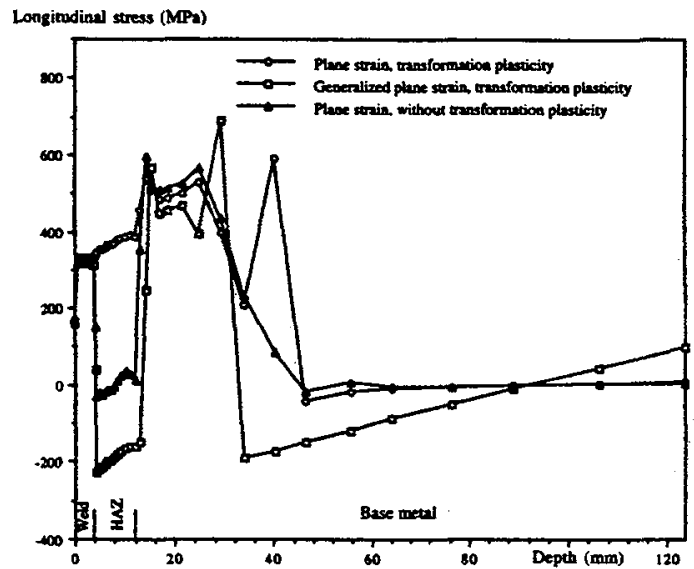

Figure 11: Longitudinal stress in depth centred on second bead with different mechanical models

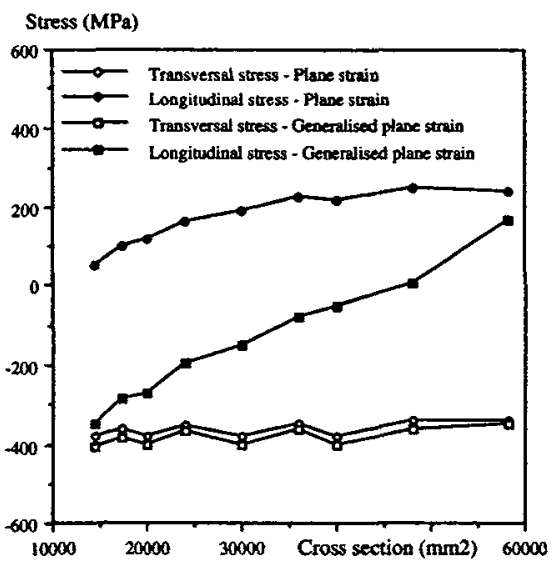

Figure 12: Maximum value of stress in $H A Z$ for different sizes of the block 


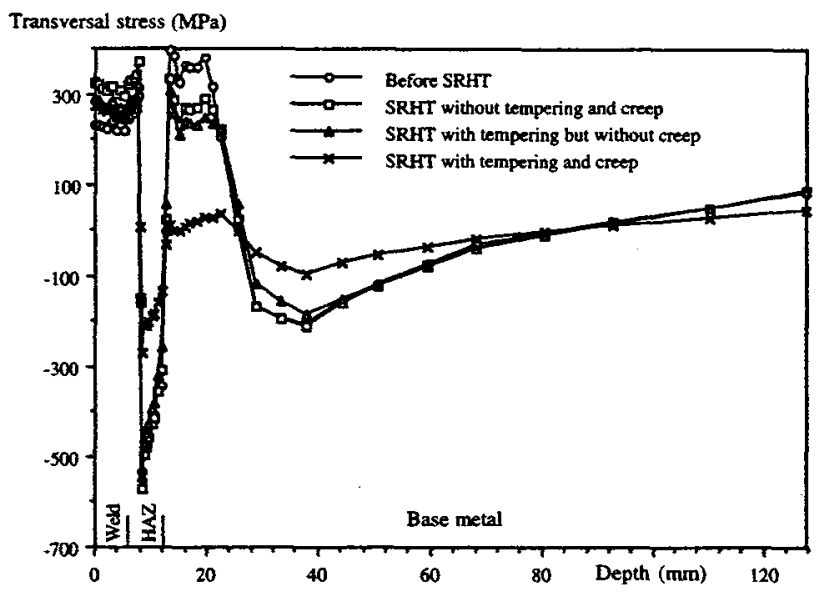

Figure 13: Transverse stress in depth centred on third bead after PWHT with different models

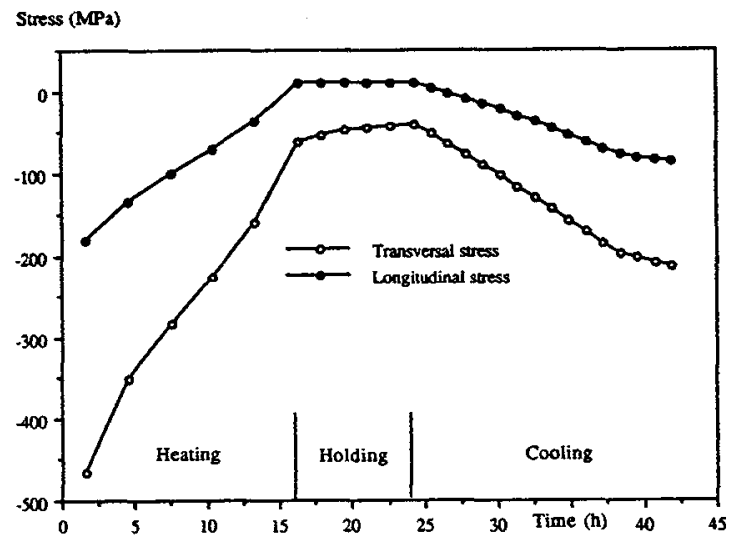

Figure 14: Variation of stress with time during PWHT using creep model.

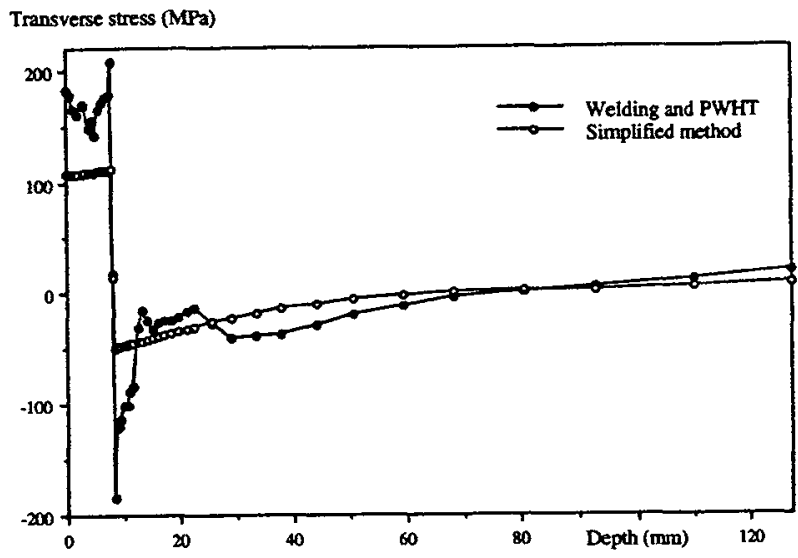

Figure 15: Transverse stress in depth centred on third bead after PWHT-Comparison with simplified method 
The post weld heat treatment can also be simulated and we show that creep was the essential factor influencing relieving, compared to tempering and plasticity.

The « simplified method " cannot be used instead of a simulation of welding and PWHT operations, due to phase transformations. But out of the HAZ, the results are fairly the same than the ones obtained with the more complex method and so they may be used in some fracture mechanics analysis.

Finally, we can consider that numerical results obtained are encouraging. We are waiting for the results of the $3 \mathrm{D}$ calculation to evaluate the longitudinal stress. It appears undoubtedly that a predictive model for temperatures based on welding parameters would be very useful. Improving methods for residual stresses measurements in depth is also necessary.

\section{References}

[1]. Leggatt, R.H. Measurement of residual stresses in clad block, TWI, 620325/1/93, July 1993.

[2]. Kockelmann, H. Residual stress measurements in a mock-up with stainless steel cladding, MPA Stuttgart, $944527000 \mathrm{Shz} / \mathrm{W}$, November 1992.

[3]. Kockelmann, H. Residual stress measurement in a mock-up with stainless steel cladding, MPA Stuttgart, $943233000 \mathrm{Shz} / \mathrm{W}$, August 1990.

[4]. SYSWELD : Manuel d'utilisation - Version 232.

[5]. Dubois ,D., Devaux, J. \& Leblond, J.B. Numerical simulation of a welding operation : calculation of residual stresses and hydrogen diffusion, ICPVT 5, September 1984, San Francisco.

[6]. Schimoeller, H.A. \& Ruge, J.L. Estimation of residual stresses in reactor pressure vessel steel specimens clad by stainless steel strip electrode, International Conference on Residual stresses in welded construction and their effects, London, 1977.

[7]. Gamha H., Frelat J. \& Wadier Y., Modélisation des contraintes résiduelles de détensionnement de la tubulure H2 d'Iran 1, note interne EDF/DER HI-73/8218, 1992. 